\title{
X. On the properties of surfaces of the second degree which correspond to the theorems of Pascal and Brianchon on conic sections
}

\section{George Salmon Esq.}

To cite this article: George Salmon Esq. (1844) X. On the properties of surfaces of the second degree which correspond to the theorems of Pascal and Brianchon on conic sections, Philosophical Magazine Series 3, 24:156, 49-51, DOI: 10.1080/14786444408644799

To link to this article: http://dx.doi.org/10.1080/14786444408644799

曲 Published online: 30 Apr 2009.

Submit your article to this journal $[\pi$

Џll Article views: 2

Q View related articles $\sqsubset$ 
an opinion from the examination of one dog and one rabbit (p. 37$)$ *.

Professor Bischoff's book affords a striking instance of the truth of a remark made by myself long since; -viz. that without a knowledge of the fact that the germinal vesicle returns to the centre of the ovum, it is not possible to learn the mode, the period, or the place of origin of the new being; or indeed to understand the ovum in any of its future phases.

In 1839 a note was added to my "Second Series" while passing through the press, concerning Bischoff's contributions to the plates accompanying $R$. Wagner's ' Physiology,' which had subsequently come into my hands. My belief was there stated that, while Bischoff's figures showed him to be in advance of others in his acquaintance with the mammiferous ovum, they also showed that he had not obtained a suite of early stages ("Second Series," l.c., p. 354). From the animus everywhere recognizable in Bischoff's book now under consideration, it is evident that the opinion expressed in that note has never been forgiven. What I then said, however, I am now compelled to repeat, and to extend to Bischoff's present communication on the ovum of the Rabbit.

There is a word of counsel too, that $I$ am under the necessity of offering Professor Bischoff. When he professes to communicate what has been done by others whose researches have preceded his, and yet thinks proper, for some reason, here and there to pass very lightly over, or altogether to omit, certain portions of the history,--he should take care that, in other parts of his book, none of these omitted portions are inadvertently permitted to creep out.

X. On the Properties of Surfaces of the Second Degree which correspond to the Theorems of Pascal and Brianchon on Conic Sections. By George Salmon, Esq.

\section{To the Editors of the Philosophical Magazine and Journal.}

\section{Gentlemen,}

T PERCEIVE that you have inserted in your last volume 1 [S. 3. vol. xxiii.] analytical demonstrations of the theorems of Pascal and Brianchon on the Conic Sections. The two theorems being connected by the theory of reciprocal polars, it is sufficient to prove one of them, and for the best analytical

* I sacrificed nearly a score of rabbits for the purpose of determining the condition in which the ova leave the ovary; and was thus enabled to show that the period of their discharge from this organ is very frequently nine or ten hours post coitum, an observation which Bischoff states to have been confirmed by his own. (See my "Second Series," l. c., pp. 310,3] 1.)

Phil. Mag. S.3. Vol.24. No. 156. Jan. 1844. 
demonstration of Pascal's I would refer to Gergonne's $A n$ nales, vol, xvii. p. 222.

I venture, however, to offer in addition the following proof of Brianchon's theorem, because it leads at once to the corresponding property in surfaces of the second degree.

Let $S=0$ be the equation of a given conic, $L=0$ that of a right line; then it is easy to see that $S-L^{2}=0$ is the equation of a conic touching the given in the two points where it is met by the line whose equation is $L=0$.

Let $S-L^{2}=0$ be the equation of another cone having also double contact with the given. Subtracting these equations, we have for the intersection of the last two conics $L^{2}-L^{2}=0$. The equations therefore of two chords of intersection are $\mathbf{L}-L_{1}=0, L+L_{1}=0$. These two chords must pass through the intersections of the two chords of contact, since their equations are satisfied by the combined equations $\mathbf{L}=0, \mathbf{L}_{1}=0$.

It would lead me into too much detail to prove that the form of the equations shows that the four lines form an harmonic pencil.

Now let a third conic have also double contact with the given. Its equation will be of the form $S-L_{\|}{ }^{2}=0$. The equations of its chords of intersection with the other two, $\mathbf{L}-\mathbf{L}_{u}=0, L_{1}+\mathbf{L}_{u}=0, L_{1}-L_{\|}=0, L_{1}+L_{u}=0$.

Evidently the three equations $\mathrm{L}-\mathrm{L}_{l}=0, \mathrm{~L}_{t}-\mathrm{L}_{\|}=0$, $\mathbf{L}-\mathbf{L}_{\|}=0$ are satisfied for the same point; also $\mathrm{L}-\mathbf{L}_{l}=0$, $\mathbf{L}_{l}+\mathbf{L}_{u}=0, \mathbf{L}+\mathbf{L}_{u}=0$, and so of the rest. Hence "if three conics have each double contact with a fourth, their six chords of intersection with each other pass three by three through the same points."

Now let each of the three touching conics degenerate into a pair of right lines, and we have Brianchon's theorem.

Now everything we have said applies almost word for word to surfaces.

The equation of a given surface of the second degree being $S=0$, that of a plane $L=0$, another surface touching the given along this plane will have its equation of the form $\mathbf{S}-\mathbf{L}^{2}=0$. A second surface also enveloped by the given has for its equation $S-L_{i}^{2}=0$. Precisely as before these two surfaces intersect each other along the planes whose equations are $\mathrm{L}-\mathrm{L}_{1}=0, \mathrm{~L}+\mathrm{L}_{l}=0$. Hence " if two surfaces of the second degree are enveloped by a third they will intersect each other in two plane curves, and the planes of intersection pass through the intersection of the planes of contact." Let a third surface be also enveloped by the surface $S$; its equation is of the form $S-L_{\|}{ }^{2}=0$, and its planes of inter- 
section $\mathrm{L}-\mathrm{L}_{\|}=0, \mathrm{~L}+\mathrm{L}_{\|}=0, \mathrm{~L}_{1}+\mathrm{L}_{\|}=0, \mathrm{~L}_{1}-\mathrm{L}_{\|}=0$. First, all six planes of intersection pass through the intersection of the three planes of contact, for their equations are all satisfied by $L=0, L_{1}=0, L_{l l}=0$. And as before they pass three by three through the same lines.

Suppose the enveloping surfaces to be cones, and we have a theorem corresponding to Brianchon's.

Form the reciprocal theorem and we get the following:-

"Take any three plane sections of a surface of the second degree; through any two of them a pair of cones can be drawn. The six vertices of these cones are in the same plane, and each set of three on the same right line." They form in fact the angles of a complete quadrilateral.

How analogous this theorem is to Pascal's, the reader will perceive more plainly if he form a figure. Mark the six sides of a hexagon inscribed in a conic A B C D E F, and the three intersections of opposite sides G H K. Now imagine the conic to represent a surface of the second degree, $\mathrm{A} \mathrm{D}, \mathrm{B} \mathrm{E}, \mathrm{C} \mathrm{F}$, three plane sections of it, A B G D E, B C H E F, C D K F A, three cones containing these sections. This theorem asserts that the three vertices $G H K$ are still on a right line.

M. Poncelet has given this property in his treatise on projective properties, but I do not think it has been perceived how analogous it is to the theorem of Pascal. M. Chasles, for example, has assigned a different theorem as the one corresponding to Pascal's. As his theorem however only asserts that certain lines are generatrices of the same hyperboloid of one sheet, the analogy can hardly be considered so perfect as in the present instance.

Trinity College, Dublin,

George Salmon.

October 5,1843 .

\section{Proceedings of Learned Societies.}

GEOLOGICAL SOCIETY.

Feb.22, A PAPER was read "On some new species of Fossil 1843*. A Chimæroid Fishes, with remarks on their general aftinities," by Sir Philip Grey Egerton, M.P., F.G.S.

The number of described species of Chimæra-soft-boned fishes of singular forms-is very small, whether existing or extinct. They were first recognised in a fossil state by Dr. Buckland in 1835. The original memoir comprised descriptions of four species; two others were added by Professor Agassiz. The list was soon afterwards augmented by two species from the Stonesfield slate, constructed by Dr. Buckland from some enigmatical specimens forwarded by the author under the impression that they had some resemblance to the subjects he was engaged upon. A ninth species came from

* The President's Annivesary Address, delivered Feb. 17, will be found in Phil. Mag. S. 3. vol. xxii. p. 511 . 